\title{
Research
}

\section{Social and Ecological Factors Influencing Attitudes Toward the Application of High-Intensity Prescribed Burns to Restore Fire Adapted Grassland Ecosystems}

\author{
$\underline{\text { David Toledo }}^{1}, \underline{\text { Michael G. Sorice }}^{2}$ and $\underline{\text { Urs P. Kreuter }}^{1}$
}

\begin{abstract}
Fire suppression in grassland systems that are adapted to episodic fire has contributed to the recruitment of woody species in grasslands worldwide. Even though the ecology of restoring these fire prone systems back to grassland states is becoming clearer, a major hurdle to the reintroduction of historic fires at a landscape scale is its social acceptability. Despite the growing body of literature on the social aspects of fire, an understanding of the human dimensions of applying high-intensity prescribed burns in grassland and savanna systems is lacking. We used structural equation modeling to examine how landowners' attitudes toward high-intensity prescribed burns are affected by previous experience with burning, perceptions of brush encroachment, land condition, proximity constraints, risk orientation, fire management knowledge and skill, access to fire management equipment, and subjective norms. Our results suggest that experience, risk taking orientation, and especially social norms, i.e., perceived support from others, when implementing prescribed burns play an important role in determining the attitudes of landowners toward the use of high-intensity prescribed burns. Concern over lack of skill, knowledge, and insufficient resources have a moderately negative effect on these attitudes. Our results highlight the importance of targeted engagement strategies to address risk perceptions, subjective norms, and landowner's concerns. With these concerns allayed, it is possible to increase the adoption of high-intensity prescribed burns that lead to landscape-scale grassland restoration and conservation.
\end{abstract}

Key Words: high-intensity prescribed burn; prescribed fire; social-ecological systems; structural model; subjective norms

\section{INTRODUCTION}

Fire suppression in grassland systems that are adapted to fire is a major factor that has contributed to recruitment of woody species worldwide (Archer et al. 1995, Briggs et al. 2002, Briggs et al. 2005). Once these woody species are established, they may be highly resilient and continue to invade, often transforming open grasslands into woodlands and, in the process, alter ecosystem functions and processes (Archer et al. 1995, Briggs et al. 2002, Briggs et al. 2005). Reverting these highly resilient, woody-invaded ecosystems to more productive grassland and savanna states requires a collapse of the degraded woodland state (Gunderson and Holling 2002), which can potentially be achieved with the reintroduction of historical fire patterns, including the periodic occurrence of high-intensity fires (Briggs et al. 2005, Taylor et al. 2012). High-intensity prescribed burns generally occur when fuel loads are high and relative humidity is very low. Although there is an increased risk of loss of control over fire when igniting them under such extreme conditions, Fuhlendorf et al. (1996), Briggs et al. (2005), and more recently Taylor et al. (2012) have demonstrated that such intense fires can result in substantial woody plant mortality. Moreover, the repeated stabilizing feedbacks of natural fire regimes, which include periodic intense fire, can facilitate the maintenance of resilient grassland and savanna states with little restoration effort and expense compared to mechanical and chemical brush control treatments (Briggs et al. 2005, Taylor et al. 2012; Fig. 1).
Fig. 1. Contrasting ecosystem trajectories from historic to present to future configurations, indicating how highly resilient systems exhibit relatively little change through time requiring limited or no human intervention. By contrast, systems exhibiting severe brush encroachment will continue to degrade and, past a certain threshold, will become increasingly resilient and resistant to reversion back to grassland or savanna state. If historical fire patterns with their stabilizing feedbacks are reintroduced and maintained, the system can be reverted back to and maintained in a grassland state with little restoration effort.

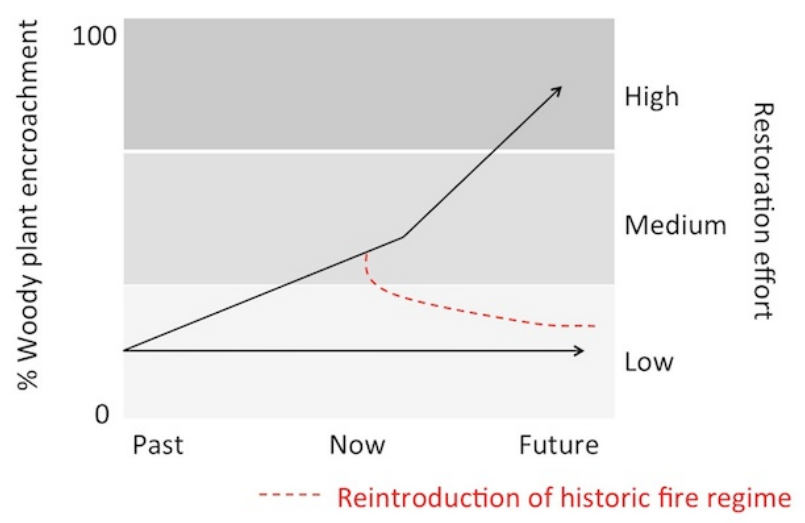

${ }^{1}$ Texas A\&M University, ${ }^{2}$ Virginia Tech 
Although the ecology of reverting these fire-prone systems back to their original state is becoming clearer, the major hurdle to reintroducing historic fire regimes at a landscape scale is a social constraint (Dombeck et al. 2004, Yoder et al. 2004). Prescribed burns, especially high-intensity prescribed burns, have been underutilized as a restoration tool primarily because of safety and legal concerns as well as cultural barriers. These issues become more pressing when wildlands are encroached upon by urbanization because this leads to greater risk of loss of life and damage to infrastructure if fires burn out of control (Vaux 1982, Davis 1990, Smeins et al. 2005). From a social resilience standpoint, early 20 th century social, economic, and political settings interacted to create an entrenched fire-suppression agenda (Agee 1974, Pyne 1982, Stephens and Ruth 2005, Steelman and Burke 2007). Ecological research recommending the need for periodic fire in many ecosystems and the increased occurrence of catastrophic fires in recent decades have begun to shift social, economic, and political considerations related to prescribed fire to a more profire agenda (Martin et al. 2008). Despite gradual shifts in perspectives and policies, the interactions of the ecological and social dimensions of applying restorative fire need illumination. We address this dearth of research by examining how landowners' attitudes toward high-intensity prescribed burns are affected by their actual experience using such fires, as well as their perceptions of brush encroachment, land condition, risk orientation, skill and knowledge about fire safety, access to equipment, and their subjective norms.

Our main assumption is that landowners first form an attitude, prior to making a decision about adopting high-intensity prescribed burning. This assumption is reasonable given that land management decisions are deliberative and voluntary. Attitude refers to an individual's positive or negative evaluation of a concept and is theorized to be a predictor of a person's intention to engage in a particular behavior (Ajzen and Fishbein 2000). In studies about prescribed burning, attitudes about applying fire were found to be affected, in part, by the risks of legal liability and short-term forage loss associated with fire (Yoder et al. 2003, Kreuter et al. 2008), or by the view that the use of prescribed burning is a dangerous and wasteful practice (Jacobson et al. 2001). However, as the understanding of the role of fire on natural systems increases, so does the acceptance of fire as a management practice (Cortner et al. 1990, Toman et al. 2006).

Previous fire use; the degree of brush encroachment; condition of the land; skill, knowledge, and equipment limitations; and constraints because of the proximity to roads and urban areas likely affect landowner attitudes toward and decisions about applying high-intensity prescribed burns. This is because prescribed burns can affect human lives, private property, roads, and air quality (Kneeshaw et al. 2004). We also expected that the amount of woody brush on a landowner's property would be related to their evaluation of land condition (good or bad), and that this evaluation, together with concerns about proximity of roads and urban areas, would directly influence their attitude toward high-intensity prescribed burns.

Concerns over the use of fire are largely associated with the perceived and actual risks of deliberately igniting a fire (Toledo et al. 2012). The disparity between perceived and objective risks vary according to biophysical factors as well as land manager experience with fire, individual and societal values (McCaffrey 2008), the context in which it occurs, attitudes, controllability, catastrophic potential, and the degree of outcome uncertainty (Slovic 1987). Therefore, risk can have different meanings depending on background, experience, and on context specific factors (Slovic 1987, Taylor et al. 1988, Plough and Krimsky 1990, Loewenstein et al. 2001), which suggests that risk perception alone is not the best predictor of whether or not a landowner would be willing to light a highintensity fire.

Subjective norms are perceptions that others want us to engage in or avoid. They influence our intention to engage in particular behaviors and, therefore, are strong motivators (Ajzen and Fishbein 2005). In the natural resources field, norms have been used to identify, plan, and communicate management decisions because of their importance in determining a person's intention to participate in a certain behavior (Ajzen and Fishbein 2000, Kneeshaw et al. 2004). More specific to our work, subjective norms as well as attitudes and beliefs have been found to have strong predictive validity in support for prescribed burn policies (Manfredo et al. 1990). It is important to point out that attitudes are not direct predictors of behavior (Ajzen and Fishbein 2000), but when measured appropriately, attitudes can predict overall patterns of behavior (Ajzen and Fishbein 1980). When attitudes are combined with measures of subjective norm, they are theorized to be a predictor of a person's intention to engage in a particular behavior (Ajzen and Fishbein 2000). Additionally, numerous studies in different fields of study have shown that subjective norms can be important determinants of behavioral intention (Taylor and Todd 1995, Yi et al. 2006, Lin 2007).

The specific objective of our work was to combine ecological and social variables using structural equation modeling to evaluate landowner attitudes toward the use of high-intensity prescribed fire. Specifically, we hypothesized that landowner attitude toward applying a high-intensity prescribed fire was associated with previous experience, brush encroachment, land condition, proximity constraints, risk taking orientation, whether the landowner had the necessary skills, knowledge, and equipment to implement a high-intensity prescribed burn, and subjective norms. 


\section{METHODS}

\section{Study sites}

The project area includes 12 different counties in 3 ecoregions of Texas: the Rolling Plains, Edwards Plateau, and the South Texas Coastal Plains (Fig. 2). We selected these counties to represent a north-south ecological gradient with vegetation transitioning from midgrass prairie/mesquite (Prosopis glandulosa) dominated savanna in the Rolling Plains; to juniper (Juniperus ashei) and oak (Quercus sp.) dominated woodlands in the Edwards Plateau; and coastal prairie and mixed brush in the South Texas Coastal Plains. All counties exhibit some level of brush encroachment by one or more of the following: honey mesquite, prickly pear cactus (Opuntia sp.), Ashe juniper, and/or huisache (Acacia farnesiana).

Fig. 2. Location of counties in each of three ecoregions where data were collected. From north to south, the ecoregions include the Rolling Plains, the Edwards Plateau, and the South Texas Coastal Plains.

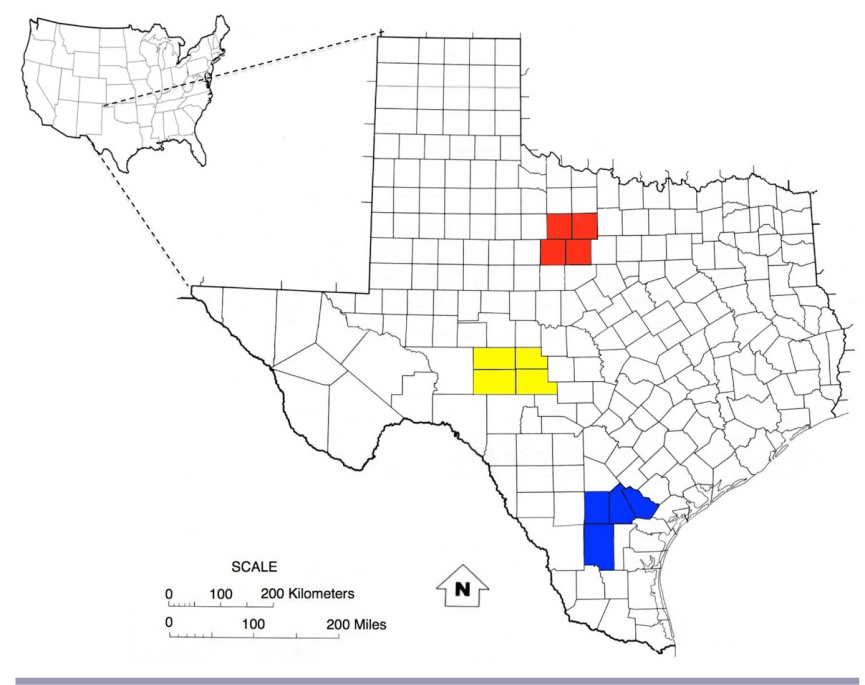

\section{Sampling}

We mailed a self-administered questionnaire to 1200 landowners to gather information about their attitudes and perceptions toward the use of fire as a rangeland management and restoration tool. Thirteen of the questionnaires were not delivered because of a change of address or the death of the landowner, thus our total was 1187 . We selected all prescribed burn association members in each county, which was usually less than 50. Then we randomly selected landowners with 20 or more hectares of land in each of the counties from county tax records, which gave us a total of 100 landowners including members and nonmembers of PBAs. The survey was implemented in the summer of 2008 using a modified repeat mailing procedure developed by Dillman (2000). We used 5 mailings that included a presurvey notification letter on day
1; a questionnaire with cover letter and a postage-paid return envelope on day 7; a reminder postcard on day 14; a replacement questionnaire with cover letter and another return envelope on day 28; and a final reminder/thank you postcard on day 42. A nonresponse bias survey was conducted six months after the final mailing of the initial survey by sending a one-page questionnaire to a randomly selected subsample of $50 \%$ of the nonrespondents.

\section{Data collection}

We collected descriptive data that included: age; gender; years of ranching experience; percent income generated from their rural property; total household income; operational characteristics such as property ownership; acres owned and/ or managed; importance of different land use activities, i.e., cattle, sheep, and goat production, wildlife ranching, and crop production with respect to management decisions; and whether a landowner had used high-intensity prescribed fire. To address our specific objectives, we also collected data on attitude toward high-intensity prescribed burning, degree of brush encroachment and land condition, proximity constraints, risk orientation, skill, knowledge and resource availability, and subjective norms using a 7-point scale. Specifically, landowners/managers were asked their level of agreement or disagreement with the statements in Table 1 (1= strongly disagree to $7=$ strongly agree).

\section{Data analysis}

For our data analysis, we pooled the data from the three ecoregions. Descriptive statistics were used to explore operational and personal characteristics of respondents. All constructs based on multiple indicators, i.e., attitude, proximity constraints, skill and resources, and social norms, were examined for internal consistency using Cronbach's alpha and confirmatory factor analysis. Cronbach's alpha values $>0.70$ generally indicate that the components of an index are reliably related to each other (Foster 2001). We first fit a measurement model to the data and then we created a structural model to test relationships between constructs. Model fit was assessed using multiple indicators including goodness of fit $\left(\mathrm{X}^{2}\right)$, absolute fit (standardized root-meansquare residual [SRMR]), parsimony correction (root-meansquare error of approximation [RMSEA]), and comparative fit (comparative fit index [CFI]; Brown 2006). Standardized regression coefficients are reported. We modified the model based on modification indices and removed paths that were not statistically significant. For each predictor, we examined both direct and indirect effects.

\section{RESULTS}

Of the 1187 surveys, we received 585 usable responses for an overall response rate of $49 \%$. Because of item nonresponse, our analysis is based on 520 cases. We also obtained 59 responses $(11 \%)$ from the initial nonrespondents to the second one-page questionnaire. Comparisons of the original survey 
Table 1. Mean response and Cronbach's alpha for indicators of experience, attitude toward high-intensity prescribed burning, degree of brush encroachment, proximity constraints, risk orientation, skill, knowledge and resource availability, and perceived support from others for 520 landowners in Texas $(1=$ strongly disagree to $7=$ strongly agree $)$.

\begin{tabular}{lcc}
\hline \hline Indicators & Mean (SD) & Cronbach's alpha \\
\hline Attitude toward high intensity prescribed fire & \\
Based on my knowledge and experience, warm season prescribed burns are & $4.53(1.66)$ \\
favorable for my land & $4.80(1.74)$ \\
$\begin{array}{l}\text { I am in favor of burning using warm season prescribed burns as a land } \\
\text { restoration tool }\end{array}$ & $5.19(1.69)$ \\
$\begin{array}{l}\text { I would be willing to apply warm season prescribed burns on my land if I was } \\
\text { shown it benefited my land }\end{array}$ & $4.65(1.77)$ \\
$\begin{array}{l}\text { If my land needs it, I will perform a prescribed warm season burn on my } \\
\text { property }\end{array}$ &
\end{tabular}

Previous experience

Have you participated in any warm season prescribed burns?

Degree of brush encroachment

What percentage of your property is currently covered by dense brush?

I consider my land to be in excellent condition

Proximity constraints

The proximity of my property to urban areas keeps me from using prescribed burning

The proximity of my property to major roadways keeps me from using

prescribed burning

Risk orientation

The chance of attaining desired management objectives using warm season prescribed burns outweighs the risks

Skill, knowledge and resource availability

I am concerned about using prescribed burning because I lack knowledge and/or experience about fire safety

I am concerned about applying prescribed burning because of lack of labor and/or equipment needed

Perceived support from others (subjective norm)

Most of my neighbors whose opinion I value would support me if I decide to implement a warm season burn on my property

My family and friends would support me if I decide to implement a warm season prescribed burn on my property
Not an index

Yes $(96.5 \%)$

Not an index

$23 \%(27)$

$4.43(1.55)$

0.87

$2.32(1.48)$

$2.49(1.54)$

$4.35(1.68)$

Not an index

$4.03(2.15)$

$4.57(2.11)$

$4.47(1.58)$

$4.90(1.66)$ and the nonresponse bias survey data revealed there were no significant differences between the respondents of the two surveys, and therefore, no response bias was detected.

\section{Descriptive statistics}

Most respondents were male $(80 \%)$ with an average age of $63+/-12$ years. Survey respondents owned, on average, 1228 hectares (standard deviation, $\mathrm{SD}=3649$; median, $\mathrm{MD}=202$; range 50 to 105,065$)$. Of the respondents, $73 \%$ were sole owners of their properties, $20 \%$ were part owners, $4 \%$ were employed land managers, and $3 \%$ did not respond to this question. Overall, respondents indicated that cattle grazing
(64\%) and wildlife ranching (29\%) were the most important activities affecting ranch management decision making. Land use activities that generated the most income for the respondents were cattle grazing (40\%), fee hunting $(14 \%)$, mineral sales and leases $(9 \%)$, and crop production $(6 \%)$.

In general, respondents reported that they were experienced landowners who have time to manage their land but have financial constraints that limit the extent to which they can implement land improvements. Mean landowner farming/ ranching experience was 31 years $(\mathrm{SD}=30 ; \mathrm{MD}=21.4)$ and only $8 \%$ of the respondents reported having no farming/ 
Fig. 3. Structural-equation model showing the direct effects of experience, brush encroachment, land condition, proximity constraints, risk taking orientation, knowledge, skill and equipment availability, and subjective norms on attitudes toward high-intensity prescribed burns for 520 landowners in 12 Texas Counties. All paths are statistically significant.

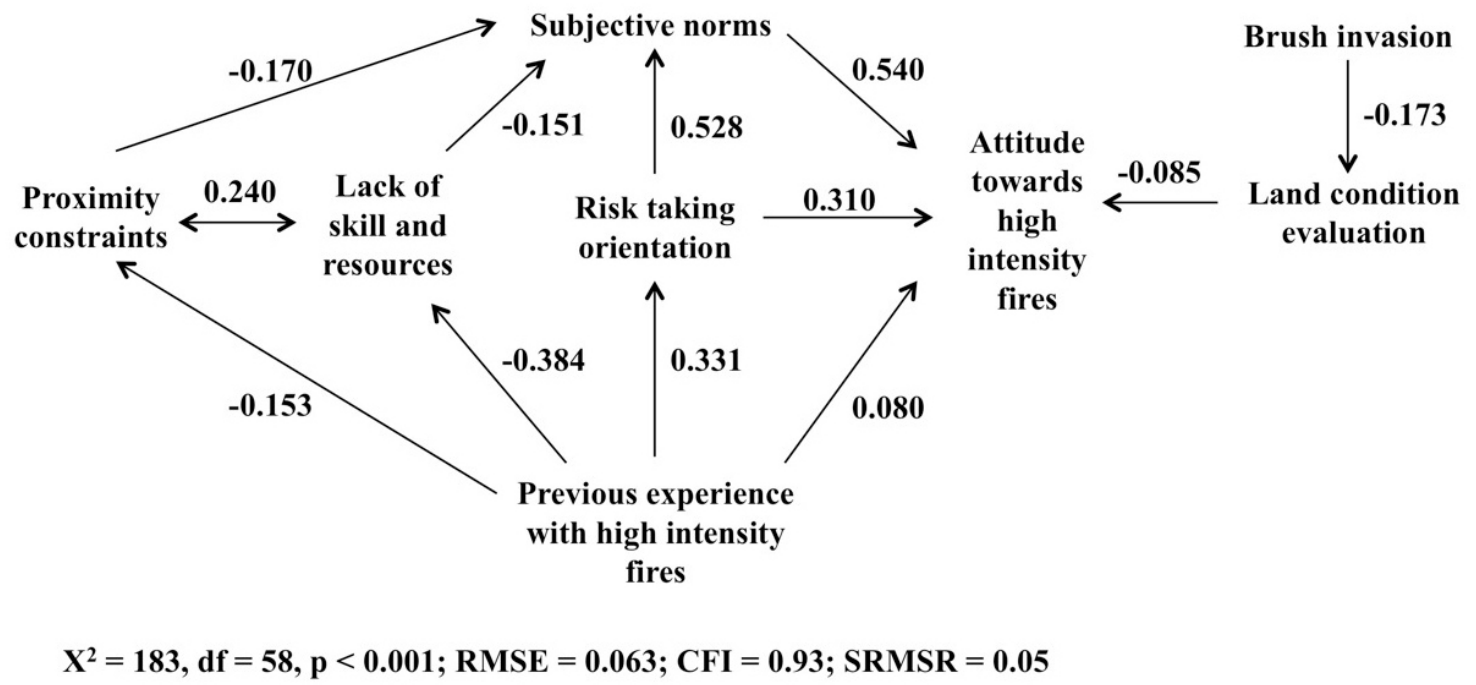

ranching experience. During the period 2003 through 2008, respondents reported that they invested an average of $\$ 49,416$ $(\mathrm{SD}=\$ 10,000 ; \mathrm{MD}=\$ 164,244.5)$ on land improvements on their properties: $69 \%$ invested between $\$ 1$ and $\$ 50,000,8.5 \%$ invested between $\$ 50,001$ and $\$ 100,000$, about $8.5 \%$ invested more than $\$ 100,000$, and $12.5 \%$ did not invest any money. Regarding 2007 income from their rural properties, 23\% of respondents reported not receiving any such income, 34\% reported that $10 \%$ or less of their income was derived from activities on their properties, and only $16 \%$ reported that the majority of their income (> 50\%) came from their rural property. Respondent income was distributed across six income categories: $\$ 25,000$ or less $(6 \%), \$ 25,000-50,000$ $(15 \%), \$ 50,001-75,000$ (17\%), \$75,001-100,000 (19\%), $\$ 100,001-500,000(36 \%)$, and over $\$ 500,000(7 \%)$. When asked whether they had performed high-intensity prescribed fires on their properties, $21.4 \%$ of landowners reported having performed these types of fires. Of these $21.4 \%, 96.5 \%$ had positive attitudes toward high-intensity prescribed fires.

\section{Structural equation model}

To test the hypothesis that a landowner's attitude toward applying a prescribed burn is associated with previous experience, brush encroachment, land condition, proximity constraints, risk taking orientation, whether the landowner has the necessary skills, knowledge, and equipment to implement a high-intensity prescribed burn, and subjective norm, we developed and evaluated a structural-equation path model. We provide results for both direct effects (Fig. 3) and indirect effects (Table 2) of different variables on attitudes toward high-intensity prescribed burns. The degree of perceived brush invasion had a weak to moderate effect on landowner evaluation of land condition $(\beta=-0.173, \mathrm{P}<0.001)$ and this evaluation was only marginally related to attitude toward highintensity prescribed burns $(\beta=-0.085, \mathrm{P}=0.006)$.

As previous experience with high-intensity prescribed fires increased, perceived constraints because of proximity to roads and urban areas as well as perceived lack of skill, knowledge, and resources decreased. The moderate to strong positive relationship between previous experience with high-intensity fires and risk taking orientation suggests that people with experience using high-intensity prescribed fires perceive that the benefits of these fires outweigh the risks of applying such fires. Previous experience with high-intensity prescribed fires had stronger indirect effects on attitudes toward high-intensity prescribed burns $(\beta=0.243, \mathrm{P}<0.001)$ than direct effects $(\beta$ $=0.080, \mathrm{P}=0.003$; Fig. 3, Table 2).

Landowner concern over lack of skills, knowledge, and resources was positively correlated with proximity constraints. As perceived proximity constraints increased, subjective norms decreased (Fig. 3), and, as concern over lack of skills, knowledge, and resources increased, subjective norms decreased (Fig. 3). Further, the indirect path from concern over lack of skill, knowledge, and resources to attitude via subjective norms was negative $(\beta=-0.082, \mathrm{P}=0.001$; Table 2) indicating that attitude is influenced by feelings of competence that are then related to perceptions of social 
Table 2. Indirect effects of items on attitude toward high-intensity prescribed burning.

\begin{tabular}{|c|c|c|c|c|}
\hline Variable & Path & $\begin{array}{c}\text { Indirect } \\
\text { Effect }\end{array}$ & SE & P-value \\
\hline \multirow[t]{5}{*}{ Previous Experience } & to Risk Orientation to Attitude & 0.103 & 0.019 & $<0.001$ \\
\hline & $\begin{array}{l}\text { to Proximity Constraints to Subjective Norm to } \\
\text { Attitude }\end{array}$ & 0.014 & 0.005 & 0.006 \\
\hline & $\begin{array}{l}\text { to Risk Orientation to Subjective Norm to } \\
\text { Attitude }\end{array}$ & 0.094 & 0.016 & $<0.001$ \\
\hline & $\begin{array}{l}\text { to Lack of Skill/Resources to Subjective Norm to } \\
\text { Attitude }\end{array}$ & 0.031 & 0.01 & 0.001 \\
\hline & Total indirect effects & 0.243 & 0.029 & $<0.001$ \\
\hline Lack of Skill/Resources & to Subjective Norm to Attitude & -0.082 & 0.024 & 0.001 \\
\hline Proximity Constraints & to Subjective Norm to Attitude & -0.092 & 0.023 & $<0.001$ \\
\hline Risk Orientation & to Subjective Norm to Attitude & 0.285 & 0.026 & $<0.001$ \\
\hline Brush Invasion & to Land Condition Evaluation to Attitude & 0.015 & 0.007 & 0.024 \\
\hline
\end{tabular}

approval. Risk-taking orientation had strong direct and indirect effects on attitude toward high-intensity prescribed burns (Fig. 3, Table 2). There was a fairly strong indirect effect between risk-taking orientation and attitude via subjective norms suggesting that perceived risk and attitudes are strongly based on a respondents' perception that their neighbors, family, and friends would support them if they decided to implement a high-intensity prescribed burn on their property.

\section{DISCUSSION}

We contribute to attitudinal research theory by explaining factors associated with landowners' attitudes toward the use of high-intensity prescribed fire as a land management tool. Our research on attitudes and norms related to high-intensity prescribed fires has the potential to promote behavioral change through specific and focused communication and engagement strategies that target attitudes or subjective norms (Toman et al. 2006). Effective natural resource management communication and engagement strategies should focus on local context-specific priorities, they should include landowners as part of an interactive process, they should target landowner normative beliefs and public attitudes, and they should be supported by factual evidence (Bright et al. 1993, Brunson and Shindler 2004, Toman et al. 2006). Our research also addresses the call for a better understanding of the social factors that affect the adoption of prescribed burning as a management tool, especially high-intensity burning, because of the important role such fires play in restoring grassland and savanna ecosystems (Fuhlendorf et al. 1996, Briggs et al. 2005, Taylor et al. 2012, Twidwell 2012).

We explored the relationships between previous experience with using high-intensity fires, land condition evaluation, proximity constraints, lack of skill and knowledge, risk-taking orientation, and subjective norms as determinants of attitude toward high-intensity burning. The major findings are that previous experience with high-intensity fires, subjective norms, and risk-taking orientation had moderate to strong effects on attitudes toward high-intensity fires. Concerns over lack of fire management skills, knowledge, and resources were found to have a weak to moderate indirect effect on attitudes, and concerns about proximity were related to attitude via subjective norms. Though we predicted that ecological context, such as land condition and location, represented constraints to the application of prescribed burning, perceived land condition as influenced by the amount of woody brush cover was weakly related to attitude. Although they are important, these constraints did not have as big an effect on attitudes toward high-intensity prescribed burns as did subjective norms and risk-taking orientation, thus indicating that landowners appear to strongly consider what people who are important to them think about prescribed burning and the perceived risks associated with it when forming attitudes toward the use of high-intensity prescribed burns.

Study results indicate that cattle grazing and wildlife ranching were the most important activities affecting ranch management decision making. Maintaining the health of these ecosystems through the periodic use of prescribed burning not only maintains and improves ecosystem function (Yoder et al. 2004, Taylor et al. 2012) and ranch values, but also improves the ability of ranches to provide the necessary forage and habitat for successful cattle and wildlife ranching operations (Taylor et al. 2012). Theory suggests that people use the information that is available to them in a reasonable manner at the time of making decisions and a person's behavior follows a logical and systematic path based on available information (Ajzen and Fishbein 1980). Therefore, from a purely rational perspective, a cost-benefit analysis based on land condition and land needs should lead landowners to a greater use of high-intensity prescribed burns because of the positive ecological effects and positive return on investment compared to mechanical and chemical treatments in many rangeland ecosystems (Van Liew et al. 2012). In their study 
of the human dimensions of fire hazards at the urban-wildland interface, Cortner et al. (1990) also noted that factors related to location, such as fire regime and fuel attributes, did not appear to be as important as predicted, and attributed this apparent lack of concern to poor understanding of landscape complexities affecting the area. Respondents of our survey generally agreed with the importance of the role of fire in complex grassland and savanna ecosystems, yet fires are not being applied as widely as they should be to restore woodlands to grasslands and savannas. The weak relationship between brush invasion and attitude shows that attitude toward highintensity prescribed burning is less a function of land condition than a combination of perceived constraints, skill level, access to resources, and, most importantly, social support.

The model developed in this study shows that although fire management skill does not directly affect attitudes, it plays a significant role by influencing risk perceptions and subjective norm, i.e., perceived support from others in applying fire. We found that skill, which in many cases is what extension programs focus on, was indirectly related to attitude through subjective norm and risk-taking orientation. These findings have important implications for programs focused on promoting the landscape-scale applications of high-intensity prescribed burning on rangelands. Although many government and extension programs have focused on skill training and education to change landowners' and land managers' attitudes toward prescribed burning, more emphasis needs to be placed on the role that subjective norm has in changing potential behaviors. Increased focus on targeting those whose opinions landowners value, such as influential landowner leaders in a community, would provide appropriate messaging strategies to have an effect on attitudes (McKenzie-Mohr 2000). This could be achieved by arranging events and demonstrations, possibly in combination with other creative programs, in which the message of the importance of prescribed fire, especially high-intensity fire, can be disseminated to these important social referents.

The key variable affecting the adoption of high-intensity prescribed burning has to do with the influence of other people who are important to the landowner, i.e., family, friends, and neighbors. These issues have been successfully addressed with the creation of prescribed burn associations. Apart from providing insurance, training, equipment, and labor (Taylor 2005, Kreuter et al. 2008), prescribed burn associations build and strengthen landowner networks, trust, and reciprocation, and enhance the social acceptability of prescribed burning as a management practice (Kreuter et al. 2008, Toledo et al. 2012) by influencing neighbors, friends, and family members. Prescribed burn associations effectively increase landowners experience with fire, which as our study suggests is an important factor that influences attitudes toward highintensity prescribed fires. Over time, this increase in support toward the use of high-intensity prescribed fire, together with the ecological benefits of applying high-intensity prescribed burns as a restoration tool, will create a reinforcing social feedback loop that will ultimately enhance the social and ecological resilience of fire adapted grassland and savanna systems.

It is important to note that risk is site and time specific. Sitespecific risk factors include the biological risks of lighting a fire, amount and flammability of fuel, chance of fire spreading to adjacent properties, and the likelihood of smoke affecting roads and urban areas. Time specific factors include season of burning and time since the occurrence of a catastrophic fire event. Different prescribed fire management approaches are needed based on site-specific conditions and risk considerations. Additionally, as climate continues to change, our ability to predict future scenarios is challenged making our capacity to implement and manage prescribed burns increasingly difficult (Bowman et al. 2009). Therefore, there is an increasing imperative to understand not only how to apply and manage high-intensity prescribed fires safely, but also how to increase adoption of high-intensity prescribed fires by more landowners, and thus restore degraded ecosystems and reduce the risks of uncontrolled wildfires.

\section{CONCLUSION}

Changing landowner attitudes toward high-intensity prescribed burning has the potential to substantially enhance landscape-scale restoration of grasslands and savannas (Taylor 2005). Our research results suggest that attitudes are very closely linked to experience, risk-taking orientation, and perceived support from other people whose opinion landowners value. Increasing social support for high-intensity prescribed burning is an important determinant of a landowner's attitude. These findings point to the delivery of targeted strategies that address two factors influencing the use of high-intensity fire: risk orientation and social support. The implementation of mechanisms that reduce real as well as perceived risk to landowners and enhance the social acceptability of applying high-intensity prescribed burns are important if the goal is to achieve landscape-scale changes. In Texas, for example, prescribed burn associations have obtained prescribed burn liability insurance policies that cover the association, its members, officers, directors, and the burn boss, effectively reducing risks derived from liability. Additionally, these prescribed burn associations increase experience with fire use and social support by building and strengthening landowner networks and trust, changing attitudes toward prescribed burning, and enhancing the social acceptability of prescribed burning as a management practice. Our research provides empirical evidence that prescribed burning associations may be an ideal mechanism to help highintensity rangeland restoration burns gain support. 
Responses to this article can be read online at: http://www.ecologyandsociety.org/issues/responses. $\mathrm{php} / 5820$

\section{Acknowledgments:}

We thank Tammy Nguyen for her contributions with data collection, entry, and error checking, the editorial staff and anonymous reviewers who helped improve this manuscript, USDA-NRCS Conservation Innovation Grant \# 38-3A75-5-180, as well as the Applied Biodiversity Science program at Texas A\&M University (NSF-IGERT grant DGE 0654377).

\section{LITERATURE CITED}

Agee, J. K. 1974. Fire management in the national parks. Western Wildlands 1:27-33.

Ajzen, I., and M. Fishbein. 1980. Understanding attitudes and predicting social behavior. Prentice-Hall, Englewood Cliffs, New Jersey, USA.

Ajzen, I,. and M. Fishbein. 2000. Attitudes and the attitudebehavior relationship: reasoned and automatic processes. European Review of Social Psychology 11:1-33. http://dx.doi. org/10.1080/14792779943000116

Ajzen, I., and M. Fishbein. 2005. The influence of attitudes on behavior. Pages 173-221 in D. Albarracin, B. T. Johnson, and M. P. Zanna, editors. The handbook of attitudes. Erlbaum, Mahwah, New Jersey, USA.

Archer, S., D. S. Schimel, and E. A. Holland. 1995. Mechanisms of shrubland expansion: land use, climate or $\mathrm{CO}_{2}$ ? Climatic Change 29(1):91-99.

Bowman, D. M. J. S., J. K. Balch, P. Artaxo, W. J. Bond, J. M. Carlson, M. A. Cochrane, C. M. D’Antonio, R. S. DeFries, J. C. Doyle, S. P. Harrison, F. H. Johnston, J. E. Keeley, M. A. Krawchuk, C. A. Kull, J. B. Marston, M. A. Moritz, I. C. Prentice, C. I. Roos, A. C. Scott, T. W. Swetnam, G. R. van der Werf, and S. J. Pyne. 2009. Fire in the Earth system. Science 324:481-484. http://dx.doi.org/10.1126/science.1163886

Briggs, J. M., G. A. Hoch, and L. C. Johnson. 2002. Assessing the rate, mechanisms, and consequences of the conversion of tallgrass prairie to Juniperus virginiana forest. Ecosystems 5:578-586. http://dx.doi.org/10.1007/s10021-002-0187-4

Briggs, J. M., A. K. Knapp, J. M. Blair, J. L. Heisler, G. A. Hoch, M. S. Lett, and J. K. McCarron. 2005. An ecosystem in transition: causes and consequences of the conversion of mesic grassland to shrubland. BioScience 55(3):243-254. http://dx. doi.org/10.1641/0006-3568(2005)055[0243:AEITCA]2.0.CO;2
Bright, A. D., M. J. Manfredo, M. Fishbein, and A. Bath. 1993. Application of the theory of reasoned action to the National Park Service's controlled burn policy. Journal of Leisure Research 25:263-263.

Brown, T. A. 2006. Confirmatory factor analysis for applied research. Guilford, New York, New York, USA.

Brunson, M. W., and B. A. Shindler. 2004. Geographic variation in the social acceptability of wildland fuels management in the western United States. Society and Natural Resources 17:661-678. http://dx.doi.org/10.1080/08941920490480688

Cortner, H. J., P. D. Gardner, and J. G. Taylor. 1990. Fire hazards at the urban-wildland interface: what the public expects. Environmental Management 13(1):57-62. http://dx. doi.org/10.1007/BF02394019

Davis, J. B. 1990. The wildland-urban interface: paradise or battleground? Journal of Forestry 88(1):26-31.

Dillman, D. A. 2000. Mail and Internet surveys: the tailored design method. John Wiley and Sons, New York, New York, USA.

Dombeck, M. P., J. E. Williams, and C. A. Wood. 2004. Wildfire policy and public lands: integrating scientific understanding with social concerns across landscapes. Conservation Biology 18:883-889. http://dx.doi.org/10.1111/ j.1523-1739.2004.00491.x

Foster, J. J. 2001. Data analysis using SPSS for Windows: a beginner's guide. Sage, Thousand Oaks, California, USA.

Fuhlendorf, S. D., F. E. Smeins, and W. E. Grant. 1996. Simulation of a fire-sensitive ecological threshold: a case study of Ashe juniper on the Edwards Plateau of Texas, USA. Ecological Modelling 90(3):245-255. http://dx.doi. org/10.1016/0304-3800(95)00151-4

Gunderson, L. H., and C. S. Holling. 2002. Panarchy: understanding transformations in human and natural systems. Island, Washington, D.C., USA.

Jacobson, S. K., M. C. Monroe, and S. Marynowski. 2001. Fire at the wildland interface: the influence of experience and mass media on public knowledge, attitudes, and behavioral intentions. Wildlife Society Bulletin 29:929-937.

Kneeshaw, K., J. J. Vaske, A. D. Bright, and J. D. Absher. 2004. Situational influences of acceptable wildland fire management actions. Society and Natural Resources 17 (6):477-489. http://dx.doi.org/10.1080/08941920490452427

Kreuter, U. P., J. B. Woodard, C. A. Taylor, Jr., and W. R. Teague. 2008. Perceptions of Texas landowners regarding fire and its use. Rangeland Ecology and Management 61:456-464. http://dx.doi.org/10.2111/07-144.1 
Lin, H.-F. 2007. Predicting consumer intentions to shop online: an empirical test of competing theories. Electronic Commerce Research and Applications 6(4):433-442. http:// dx.doi.org/10.1016/j.elerap.2007.02.002

Loewenstein, G. F., E. U. Weber, C. K. Hsee, and N. Welch. 2001. Risk as feelings. Psychological Bulletin 127 (2):267-286.

Manfredo, M. J., M. Fishbein, G. E. Haas, and A. E. Watson. 1990. Attitudes towards prescribed fire policies. Journal of Forestry 88(7):19-23.

Martin, W. E., C. Raish, and B. Kent, editors. 2008. Wildfire risk: human perceptions and management implications. Resources for the Future, Washington, D.C., USA.

McCaffrey, S. 2008. Understanding public perspectives of wildfire risk. Pages 11-22 in W. E. Martin, C. Raish, and B. Kent, editors. Wildfire risk, human perceptions and management implications. Resources for the Future, Washington, D.C., USA.

McKenzie-Mohr, D. 2000. Fostering sustainable behavior through community-based social marketing. American Psychologist 55:531-537. http://dx.doi.org/10.1037/0003-066X.55.5.531

Plough, A., and S. Krimsky. 1990. The emergence of risk communication studies: social and political context. Pages 223-231 in T. S. Glickman and M. Gough, editors. Readings in risk. Resources for the Future, Washington, D.C., USA.

Pyne, S. J. 1982. Fire in America: a cultural history of wildland and rural fire. Princeton University Press, Princeton, New Jersey, USA.

Slovic, P. 1987. Perception of risk. Science 236:280-285. http://dx.doi.org/10.1126/science.3563507

Smeins, F. E., S. D. Fuhlendorf, and C. A. Taylor, Jr. 2005. History and use of fire in Texas. Pages 6-16 in D. Rollins, editor. Fire as a tool for managing wildlife habitat in Texas. Texas Cooperative Extension, San Angelo, Texas, USA.

Steelman, T. A., and C. A. Burke. 2007. Is wildfire policy in the United States sustainable? Journal of Forestry 105 (2):67-72.

Stephens, S. L., and L. W. Ruth. 2005. Federal forest-fire policy in the United States. Ecological Applications 15:532-542. http://dx.doi.org/10.1890/04-0545

Taylor, Jr., C. A. 2005. Prescribed burning cooperatives: empowering and equipping ranchers to manage rangelands. Rangelands 27(1):18-23. http://dx.doi.org/10.2111/1551-501X (2005) $27<18:$ PBCEAE $>2.0 . C O ; 2$

Taylor, J. G., E. H. Carpenter, H. J. Cortner, and D. A. Cleaves. 1988. Risk perception and behavioral context: U.S. forest service fire management professionals. Society and Natural Resources 1:25-268. http://dx.doi.org/10.1080/08941928809380657

Taylor, S., and P. A. Todd. 1995. Understanding information technology usage: a test of competing models. Information System Research 6(2):144-176. http://dx.doi.org/10.1287/ isre.6.2.144

Taylor, Jr., C. A., D. Twidwell, N. E. Garza, C. Rosser, J. K. Hoffman, and T. D. Brooks. 2012. Long-term effects of fire, livestock herbivory removal, and weather variability in Texas semiarid savanna. Rangeland Ecology and Management 65 (1):21-30. http://dx.doi.org/10.2111/REM-D-10-00124.1

Toledo, D., U. P. Kreuter, M. G. Sorice, and C. A. Taylor, Jr. 2012. To burn or not to burn: ecological restoration, liability concerns, and the role of prescribed burning associations. Rangelands 34(2):18-23. http://dx.doi.org/10.2111/RANGELANDSD-11-00037.1

Toman, E., B. Shindler, and M. Brunson. 2006. Fire and fuel management communication strategies: citizen evaluations of agency outreach activities. Society and Natural Resources 19 (4):321-336. http://dx.doi.org/10.1080/08941920500519206

Twidwell, D. L. 2012. From theory to application: extreme fire, resilience, restoration, and education in social-ecological disciplines. Dissertation. Texas A\&M University, College Station, Texas, USA.

Van Liew, D., J. R. Conner, U. P. Kreuter, and R. Teague. 2012. An economic comparison of prescribed extreme fire and alternative methods for managing invasive brush species in Texas: a modeling approach. Open Agriculture Journal 6:17-26. http://dx.doi.org/10.2174/1874331501206010017

Vaux, H. J. 1982. Forestry's hotseat: the urban/forest interface. American Forests 88:44-46.

Yi, M. Y., J. D. Jackson, J. S. Park, and J. C. Probst. 2006. Understanding information technology acceptance by individual professionals: toward an integrative view. Information and Management 43(3):350-363. http://dx.doi. org/10.1016/j.im.2005.08.006

Yoder, J., D. Engle, and S. Fuhlendorf. 2004. Liability, incentives, and prescribed fire for ecosystem management. Frontiers in Ecology and the Environment 2:361-366. http:// dx.doi.org/10.1890/1540-9295(2004)002[0361:LIAPFF]2.0.CO;2

Yoder, J., M. Tilley, D. Engle, and S. Fuhlendorf. 2003. Economics and prescribed fire law in the United States. Applied Economic Perspectives and Policy 25(1):218-233. http://dx.doi.org/10.1111/1467-9353.00055 